\title{
New haemostat in thoracic surgery
}

\author{
Habal $\mathrm{P}^{1}$, Omran $\mathrm{N}^{1}$, Kovacicova $\mathrm{K}^{2}$, Mandak $\mathrm{J}^{1}$ \\ Charles University in Prague, Faculty of Medicine in Hradec Kralove and University Hospital in Hradec Kralove, \\ Department of Cardiac Surgery, Hradec Kralove, Czech Republic.phabal@seznam.cz
}

\begin{abstract}
INTRODUCTION: The authors present the results of a promising method to reduce peroperative bleeding in thoracic surgery within large thoracic surgical interventions. Usage of a resorbable haemostat on the basis of oxidized cellulose in the form of cotton wool may minimize the cause of bleeding, mainly in patients with postinflammatory thoracic complications. The strong point of this material is its easy application and malleability. Another advantage is the long-term antibacterial effect caused by lowering $\mathrm{pH}$ during its biodegradation.

AIM: Retrospective evaluation of post-operative blood losses, time of thoracic drainage, length of hospitalisation, and development of inflammatory indicators between groups using and not using haemostats.

METHODOLOGY: Agroup consisted of 48 patients (groupA), who underwent operation for post-inflammatory thoracic complications and where haemostat was used. Using the pair selection method, 48 patients were selected to the control group B, where no haemostats were applied during operation. The selection depended on a similar demographic profile, identical diagnosis, and a type of operations. Post-operational blood loss, dynamics of haematological profile, time of thoracic drainage, blood parameters value, inflammatory response of the organism, and length of hospitalisation. RESULTS: A key differentiation of dynamics in development was found between the groups in the concentration of haemoglobin and haematocrit in the post-operative period, in the time of thoracic drainage, and in total length of hospitalisation. A sudden rise of CRP serum values in the group A after 12 hours after application of haemostat was recorded, most probably as manifestation of the aseptic pleuritic (Tab. 4, Fig. 1, Ref. 16). Text in PDF www.elis.sk.

KEY WORDS: peroperative bleeding, postoperative bleeding, fibrothorax, Traumacel FAM OcW.
\end{abstract}

\section{Introduction}

Despite timely administered antibiotic treatment (ATB) of pulmonary infection, there was a group of patients, in whom the conservative procedure failed. The original parapneumotic effusion turned into the thoracic empyema. The incidence rate is about $15 \%(1)$. This results in an origin of fibrothorax and the dysfunction of pulmonary parenchyma. Late indication of surgical intervention leads to cardiac failure and arising cor pulmonale (2). Operations included various stages of resectional performance of the parenchyma affected with chronic post-inflammatory changes, and performance on parietal and visceral pleura - decortication and pleurectomy (3). Although the higher blood loss from nonsurgical sources may be expected, it is suitable to use various local haemostatic preparations.

${ }^{1}$ Charles University in Prague, Faculty of Medicine in Hradec Kralove and University Hospital in Hradec Kralove, Department of Cardiac Surgery, and ${ }^{2}$ The Merciful Brothers Hospital in Brno, Department of Surgery, Czech Republic

Address for correspondence: P. Habal, MD, PhD, Charles University in Prague, Faculty of Medicine in Hradec Kralove and University Hospital in Hradec Kralove, Department of Cardiac Surgery, Hradec Kralove, Czech Republic

Acknowledgements: The present work was supported by the programme PRVOUK P37/4 and the MH CZ-DRO (UHHK, 00179906).

\section{Material}

Since January 2009 to December 2013, at Cardiac Surgery Clinic of Medical Faculty of Charles University and Teaching Hospital in Hradec Králové, 48 patients of group A had surgery, 26 males and 22 females aged $66.4 \pm 3.2$ years. The control group B without a local haemostat consisted of 48 patients chosen by the pair selection method, 23 males and 25 females aged $71.6 \pm 2.3$ years. The interval of selection was from January 1992 to December 2003. The selection depended on similar demographic profile, identical diagnosis, and similar surgical performance Table 1. All patients suffered pleumonary infection with complicating inflammation of the pleural space. The treatment was supplemented with a thoracic drainage with rinsing the pleural space with the aseptic

Tab. 1. Demographic data of patients with diagnoses overview - groups $A$ and $B(n=48)$.

\begin{tabular}{lccc}
\hline & Group A & Group B & p \\
\hline Male patients n (\%) & $26(54.2 \%)$ & $23(47.9 \%)$ & n.s. \\
Female patients n (\%) & $22(47.9 \%)$ & $25(52.1 \%)$ & n.s. \\
Age (years) & $66.4 \pm 3.2$ & $71.6 \pm 2.4$ & n.s. \\
Body mass index (BMI) & $25(22-29)$ & $28(23-31)$ & $<0.05$ \\
Thoracoscore* & $5.1(2.7-8.2)$ & $6.4(5.2-7.9)$ & $<0.05$ \\
Non-specific inflammatory aetiology (\%) & $25(52 \%)$ & $29(60.4 \%)$ & n.s. \\
$\quad$ - fibrothorax n (\%) & $18(36.7 \%)$ & $15(31.2 \%)$ & $<0.05$ \\
- trapped lung** $\mathrm{n}(\%)$ & $5(10.4 \%)$ & $5(10.4 \%)$ & n.s. \\
$\Sigma$ n (\%) & 48 & 48 & n.s. \\
\hline
\end{tabular}


Tab. 2. Type of surgery in groups $A$ and $B(n=48)$.

\begin{tabular}{lccc}
\hline & Group A & Group B & $\mathrm{p}$ \\
\hline Decortication \& Pleurectomy n (\%) & $39(81.2 \%)$ & $41(85.4 \%)$ & n.s. \\
Thoracoplasty & $5(10.4 \%)$ & $1(2.1 \%)$ & $<0.05$ \\
Pleurostomy & $1(2.1 \%)$ & $3(6.3 \%)$ & $<0.05$ \\
Myoplasty & $3(6.3 \%)$ & $3(6.3 \%)$ & n.s \\
\hline
\end{tabular}

Tab. 3. Selected postoperative values in groups $A$ and $B(n=48)$.

\begin{tabular}{lccc}
\hline & Group A & Group B & $\mathrm{p}$ \\
\hline Haemoglobin in 12 hrs (g.l - $^{-1}$ & $121(89-136)$ & $98(74-108)$ & $<0.01$ \\
Haemoglobin in 24 hrs (g.1 & $120(85-137)$ & $107(87-125)$ & $<0.05$ \\
Haematocrit in 12 hrs (\%) & $29(25-35)$ & $19(14-23)$ & $<0.01$ \\
Haematocrit in 24 hrs (\%) & $28(20-36)$ & $22(19-27)$ & $<0.05$ \\
Number of EBR (TU) & $2(0-3)$ & $5(2-8)$ & $<0.01$ \\
\hline
\end{tabular}

Tab. 4. Hospitalization characteristics of group $A$ and $B(n=48)$.

\begin{tabular}{lccc}
\hline & Group A & Group B & $\mathrm{p}$ \\
\hline Time of stay in ICU (hrs) & $29(8-60)$ & $44(11-72)$ & $<0.01$ \\
Time of thoracic drainage (hrs) & $120(106-156)$ & $216(72-336)$ & $<0.01$ \\
Total losses HD (ml) & $1150(800-1750)$ & $2850(1450-6850)$ & $<0.001$ \\
Time of hospitalisation (days) & $9(7-12)$ & $16(9-28)$ & $<0.001$ \\
Mortality n (\%) & 0 & $2(4.2 \%)$ & - \\
\hline
\end{tabular}

Group A - with haemostat, Group B - without haemostat

solution. In group A in 6 cases (12.5\%) and in group B in 4 cases $(8.3 \%)$ streptokinase was administered intrapleurally. The operation was indicated in various stages of fibrous pleural development changes, a selection of patients already developed trapped lung syndrome. In 2 (4.2\%) patients of group A, before pleurectomy (12 and 18 days), thoracoscopic drainage (VTS) of the pleural cavity was performed with an unsatisfactory result (Tab. 2).

\section{Method}

The operations were performed from posterolateral thoracotomy under a general anaesthesia and antibiotics coverage, according to former results of bacteriological findings. In patients with thoracoplasty, a resection of parts of 4 th -7 th ribs was performed at the beginning. Asimilar tactics were chosen in the patients with pleurectomy. For myoplasty, a group of muscles musculus serratus anterior was used most often. In the group B, a non-surgical type of bleeding was solved by applying hot drapes on the area after pleurectomy; in the group A oxidized cellulose was used. The material was applied in a dry form, partly on the pulmonary area after decortication, partly on the inner area of the pleural cavity after pleurectomy. On average, $150 \mathrm{cmq}$ of haemostat, which makes $2-8 \mathrm{~g}$ (1-4 packaging) was used per one patient. Retrospectively, total postoperative blood loss, dynamics of haematological profile, time of thoracic drainage, blood parameters, general inflammatory response of the organism, and length of hospitalisation were compared in both groups.

\section{Results}

There was no difference between the groups in demographic data and the types of surgery. In both groups, the dominant performance was pleurectomy and decortication, sometimes with aseptic resection of changed pulmonary parenchyma. There were recorded statistically significant differences in total losses through the chest tube. Aremarkably higher loss was in the group $B(p<0.00041$. This corresponded with a longer time of thoracic drainage $(p<0.0078)$. A different dynamics in development of blood count was significantly manifested. In the group B, a significant drop was recorded in 12 hours after the operation $(\mathrm{p}<0.0057)$. This influenced the different number of blood transfusions ( $\mathrm{p}<0.0048$ ). Diffuse blood loss took part in a higher morbidity rate, prolonged stay in the intensive care unit $(\mathrm{p}<0.0027)$ as well as the hospitalization $(\mathrm{p}<0.00087)$. Tables 3 and 4 showed monitored characteristics. In the group B, two deaths were recorded, namely of heart failure after acute myocardial infarction and massive pulmonary embolization. Adifferent development in CRP values as the indicator of total inflammatory changes can be explained by the response to the application of extraneous substance, which provokes aseptic pleuritis. This improves the adherence of expanded pulmonary tissue to the thoracic wall after pleurectomy and decortication (Fig. 1). This summary can be considered the pilot study and focus on the course of local inflammatory reaction in the pleural cavity after haemostat was applied.

\section{Discussion}

In $2 \%$ of patients, pulmonary infections are accompanied by pleural effusions, which often causes development of complications (6). Both groups consisted of patients with late or inadequate treatment of primary inflammatory pulmonary complications.

When the effusion arises, an early evacuation and re-expansion of pulmonary tissue by thoracic drainage is the only method to prevent its contamination in case of bacteraemia or transfer of infection from affected pulmonary issue (7).

Fibrotic changes in the pleural cavity following an inflammatory process increase the morbidity rate of patients. Progression of respiratory insufficiency occurs. In case of late surgical intervention, this state can result in right-hand heart failure based on chronic cor pulmonale. In this group of patients, more demanding peroperative course is assumed. There is a higher blood loss from surgically difficult-to-treat areas in the post-operative period.

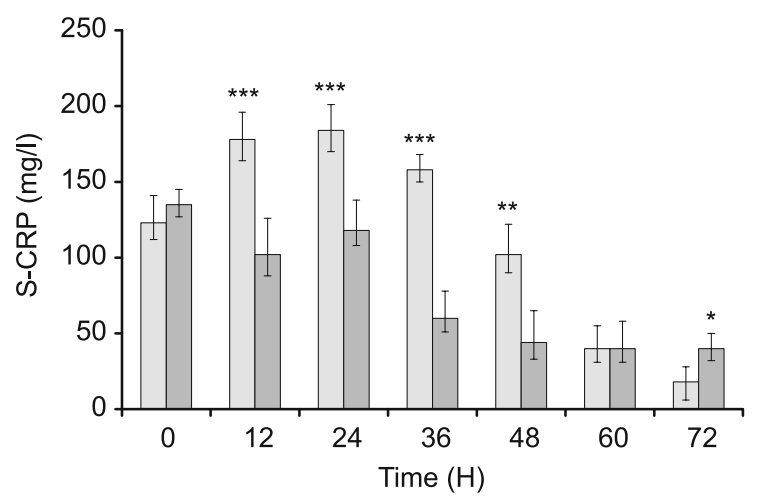

$\square$ Group A $\quad \square$ Group B

Fig. 1. Development of CRP values in serum. 


\section{6-508}

Timely indicated VTS curing of the pleural cavity from fibrinous coating may prevent from later complications (8). The question arises on whether to prefer more effective and treatment accelerating VTS or local fibrinolytic treatment. In case of its indication after the fibrinolysis, no good results can be expected, as confirmed in our experience.

When a pyogenic membrane with CT image showing the thickened pleura arises, development of the disease reached conservative irreversibility with the necessity of decortication and pleurectomy (9). Decisive factor is a correct timing of the operation in order to remove the empyema sac before fibrothorax arises. The most suitable is the period of 4-6 weeks after the inflammation. In case of late decortications, there is a threat of pulmonary parenchyma injury (10). If an inflammatory process keeps running in the pleural cavity, decortication is not indicated. There is a risk of spreading the infection on the pulmonary surface with origin of new adhesions.

In the past, the methods of open therapy for local treatment of purulent content with antiseptics were used, introduced by Leo Eloesser in 1935 (11). Nowadays, it is rarely used to treat empyema of thorax, caused by Staphylococcus aureus, resistant to methicillin (MRSA)

(12). Sometimes it is not possible to avoid partial resection of ribs (13). The reason is to build a larger contact between pulmonary surface and tissue layers of the thoracic walls, which are rich in vessels. Penetration of ATB into the pleural cavity improves. The method was introduced by Schede in 1890, before the era of antituberculous drugs, for collapse therapy of pulmonary cavities (14). Myoplasty or omentoplasty is rarely used in treatment of inflammatory fibrothorax, where the cause of inflammation is a bronchial fistula after the pulmonary resection (15).

In patients, who suffered serious inflammatory affection, we cannot prevent the bleeding of various intensity despite using tissue saving techniques of operation. A commonly used procedure is administration of the haemophilic plasma and trombocytes, saturation of the organism with missing factors of coagulation cascade, and blood transfusion. Drainage through a chest tube does not consist only of bleeding; there is also a share of lymphorrhoea in case of damaged lymphatic passages placed in subplureal locations (16). These losses can be eliminated only by using local haemostats. The method of tamponade using drapes requires surgical revision in order to remove or exchange within a second look operation.

\section{Conclusion}

Methods used to reduce the bleeding and blood transfusions saving are various. The method of autotransfusion or haemodilution is in the presented group of patients applicable to a limited extent due to polymorbidity after a chronic inflammation. Most of the patients suffered from a low blood count already in preoperative period. The blood recuperation or usage of cell-saver is not suitable, it is not extensive bleeding, but diffusive, surgically difficult-to-treat bleeding connected with lymphorrhoea.

Local haemostats offer promising haemostasis. Preparations on basis of oxidized cellulose Traumastem FAM OcW (FAM fibrillar advanced material, OcW - oxidized cotton pool) show very good adhesive and haemostatic features; the bleeding stops within 2-6 minutes.

Theadvantage of using in the pleural cavity originally affected by inflammation is antibacterial effect against a wide range of gram-positive and gram-negative bacteria. This effect arises due to drop of $\mathrm{pH}$ during cellulose biodegradation.

Spectrum of patients moves to higher age brackets. Therefore, every method, which reduces bleeding, decreases the number of blood transfusions, and quickens the mobilisation of a patient, is very beneficial. Elimination of blood transfusion is still more important for both medicinal and economic reasons.

\section{References}

1. Marel M, Zrustova M, Stastny B. The incidence of pleural effusion in a well-defined region. Epidemiologic study in central Bohemia. Chest 1993; 104: 1486-1489.

2. Klopp M, Dienemann H. Pleural empyema: surgical treatment. Dtch Med Wschr 2005; 130: 530-533.

3. Deslauriers J, Perrault LP. Fibrothorax and decortication. In PEARSON, F.G., (Ed.), Thorax surgery. New York: Churchill Livingstone, 1995; $1107-1120$.

4. Habal P, Omran N, Mandak J. Controlled Hemostasis in Thoracic Surgery Using Drugs with Oxidized Cellulose. Acta Medica (Hradec Králove) 2011; 54 (4):153-156.

5. Štětina M, Šimek J, Mand'ák J, Habal P. Ovlivnění krevních ztrát po dekortikaci plicní tkáně a pleurektomii lokální aplikací aprotininu. Rozhl Chir 2003; (82)4: 209-213.

6. Marel M. Epidemiology of pleural effusion. In: Lodden-Kemper, R., Antony, V.B. (Eds). Pleural Diseases. Sheffield: ERS Journals, 2002; 146-157.

7. Sasse S, Nguyen TK, Mulligan M. The effect of early chest tube placement on empyema resolution. Chest 1997; 111: 1679-1683.

8. Wurnig PN, Wittmer V, Pridun NS. Videoassisted Thoracic Surgery for pleural empyema. Ann Thoracic Surg 2006; 81 (1): 309-313.

9. Melloni G, CarrettaA, Ciriaco P. Decortication for chronic parapneumonic empyema: results of a prospective study. World J Surg 2004; 28: 488-493.

10. Wilson AG. On the history of disease concepts: the case of pleurisy. History Sci 2000; 38: 271-319.

11. Thourani VH, Lancaster RT, Mansour KA. Twenty-six years of experience with the modified cloesser flap. Ann Thor Surg 2003; 76: 672-676.

12. Kutsuragi N, NakajimaY, Shiraishi Y. Chronic tuberculous methicillin-resistant Staphylococcus aureus (MRSA) empyema with bronchopleural fistulae treated by open windows thoracostomy followed by thoracoplasty and latissimus dorsi muscle transposition. Kyobu Geka, 2005; 58: 1121-1124.

13. Kremmer K, Platzer W. Chirurgische Operationslehre. Band 2. Thorax. Stuttgart: Georg Thieme Verlag, 1999; 314.

14. Peppas G, Molnar TF, Jeyasingham K. Thoracoplasty in the context of current surgical practice. Ann Thorac Surg 1993; 56: 903-909.

15. Clagett OT. Changing aspects of the aetiology and treatment of pleural empyema. Surg Clin N Am 1973; 53: 863-866.

16. Agostini E, Zocchi L. Mechanical coupling and liquid exchanges in the pleural space. Clin Chest Med 1998; 19: 241-260.

Received July 11, 2014. Accepted February 28, 2015. 